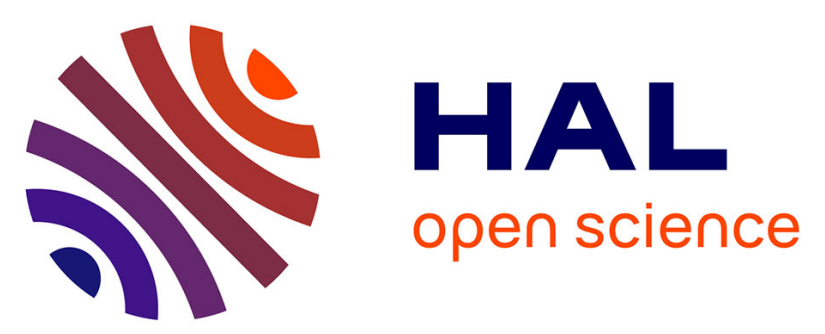

\title{
RBS and NRA analysis for films with high growth rate prepared by atomic layer deposition
}

\author{
B. Xia, J.J. J Ganem, S. Steydli, H. Tancrez, Ian Vickridge
}

\section{To cite this version:}

B. Xia, J.J. J Ganem, S. Steydli, H. Tancrez, Ian Vickridge. RBS and NRA analysis for films with high growth rate prepared by atomic layer deposition. Nuclear Instruments and Methods in Physics Research Section B: Beam Interactions with Materials and Atoms, 2021, 489, pp.20-25. 10.1016/j.nimb.2020.12.015 . hal-03264045

\section{HAL Id: hal-03264045 \\ https://hal.sorbonne-universite.fr/hal-03264045}

Submitted on 17 Jun 2021

HAL is a multi-disciplinary open access archive for the deposit and dissemination of scientific research documents, whether they are published or not. The documents may come from teaching and research institutions in France or abroad, or from public or private research centers.
L'archive ouverte pluridisciplinaire HAL, est destinée au dépôt et à la diffusion de documents scientifiques de niveau recherche, publiés ou non, émanant des établissements d'enseignement et de recherche français ou étrangers, des laboratoires publics ou privés. 
RBS and NRA analysis for films with high growth rate prepared by atomic layer deposition

B. Xia 1, J.J. Ganem 1, S. Steydli 1, H. Tancrez 1, I. Vickridge 1.

SAFIR, Institut de NanoSciences de Paris, UMR7588 du CNRS et Sorbonne Université - Paris (France)

\begin{abstract}
We present the design and operation of a specialized Atomic Layer Deposition (ALD) system, dedicated to stable isotopic tracing experiments of oxide film growth, using isotopically labelled water as the oxide reactant. A small chamber volume allows operation with only very small quantities of water vapor, minimising the consumption of the isotopically labelled water. The first results for growth of $\mathrm{ZnO}$ and $\mathrm{TiO}_{2}$ using Diethlyzinc (DEZ) and Tetrakis(dimethylamino)titanium (TDMAT) as the zinc and titanium precursors, and unlabelled water as reactant, are presented, to establish the growth conditions for stoichiometric $\mathrm{ZnO}$ and $\mathrm{TiO}_{2}$ on silicon. Absolute film compositions and thickness are determined by RBS and NRA as a function of vapor pulse duration, number of ALD cycles and substrate temperature. Physical thickness is determined by ellipsometry. The first results obtained for growth of $\mathrm{ZnO}$ using water highly enriched in ${ }^{18} \mathrm{O}$ are also presented.
\end{abstract}

Key words: Atomic Layer Deposition (ALD), Thin films, multilayer, RBS

\title{
1.Introduction
}

Atomic layer deposition (ALD) is a technique to prepare high quality thin films, with a controlled thickness and uniform composition through sequential self-terminating gas reactions [1,2]. The ALD technique has been used to prepare water and oxygen barrier layers [3], conductive electronic films [4], transistor dielectric layer [5] and surface passivation layer [6] with applications in microelectronics [7], solar batteries [8] and flexible electronics [9]. ALD also allows growth on high aspect ratio structures, allowing conformal coating of nanoparticles [10], and nanoporous [11] and nanostructured systems [12]. Due to great potential applications of ALD films, much attention has been paid to industrialization of the ALD technique. Yong-June Choi's team has developed an ALD machine for depositing $\mathrm{ZnO}$ and study its growth mechanism, the growth rate of $\mathrm{ZnO}$ films could reach to about $1.5 \AA$ /cycles at $140^{\circ} \mathrm{C}$ [13]. David H. Levy designed a fast opening air atomic layer deposition system for preparing the films, which has a maximum growth rate for $\mathrm{ZnO}$ films of approximately $1.2 \AA$ /cycle [14]. Seong Keun Kim who used the commercial ALD system (Ever-tek, Plus-100), prepared oxide films and obtained a maximum growth rate of almost $2 \AA /$ cycle for $\mathrm{ZnO}$ [15]. Although the development of commercial and home-made ALD equipment allows growth of many kinds of thin films, the film growth rates remain relatively low compared to those obtained by the CVD process. So, there is still a lot of room for the further development and promotion of atomic layer deposition equipment.

In this paper, we introduce a novel ALD chamber combining a small volume, hot substrate/cool chamber and precursor cross-flow design. This design minimizes premature precursor decomposition and allows economic use of expensive isotopically enriched precursors for growth mechanism studies. 
We chose first to grow $\mathrm{ZnO}$ and $\mathrm{TiO}_{2}$ films because growth of these is well established, with numerous applications, and in addition, the high mass of the cation (compared to the very widely grown $\mathrm{Al}_{2} \mathrm{O}_{3}$ ) substantially simplifies RBS measurements. Films were grown from water and DEZ ( $\mathrm{ZnO}$ films) or TDMAT ( $\mathrm{TiO}_{2}$ films) precursors. Absolute film elemental compositions were determined by RBS, and NRA, and film physical thickness was determined by ellipsometry. The effects of the number of ALD cycles, precursor pulse duration and substrate temperature were investigated. We also grew some films using water highly enriched in ${ }^{18} \mathrm{O}$.

\section{Experiment}

\subsection{System description}

The home-made ALD system consists of three parts: precursor, oxidant and carrier gas handling system, cross-flow design hot substrate/cold reaction chamber and a pumping system controlled by an in-house Labview control system (as shown in Fig.1a). The DEZ and TDMAT precursor gases and the water vapour are controlled by fast valves. The flux of $\mathrm{N}_{2}$ carrier gas is maintained by mass flow controller (MFC). A compact manifold system connects several precursor gas bottles to the single cross-flow gas inlet to the chamber. In our cross-flow design, gas enters the chamber through a nozzle nearly parallel to the sample surface, and is evacuated through the opposing face of the chamber by a dry pumping system. Compared with the traditional cross flow gas entrance our system has a small angle with sample surface. Such cross-flow design leads to more homogeneous film growth. The inlet nozzle has a wedge design, which has been shown to improve stability and homogeneity, and to increase deposition efficiency [16]. The sample holder is insulated from the chamber by a ceramic surround, and heated from the bottom by a resistive element. The sample surface temperature is inferred from the furnace thermocouple, via a careful series of calibration measurements. The passage of carrier gas and precursors in the chamber influences the target and chamber temperatures through convection and conduction. In order to limit transient temperature variations during the ALD sequence, we have developed a temperature control system based on a predictive temperature model. A typical series of precursor pressure pulses vs time includes water vapour pulse and purge time, and precursor pulse and purge time as shown on Fig.1b.

a
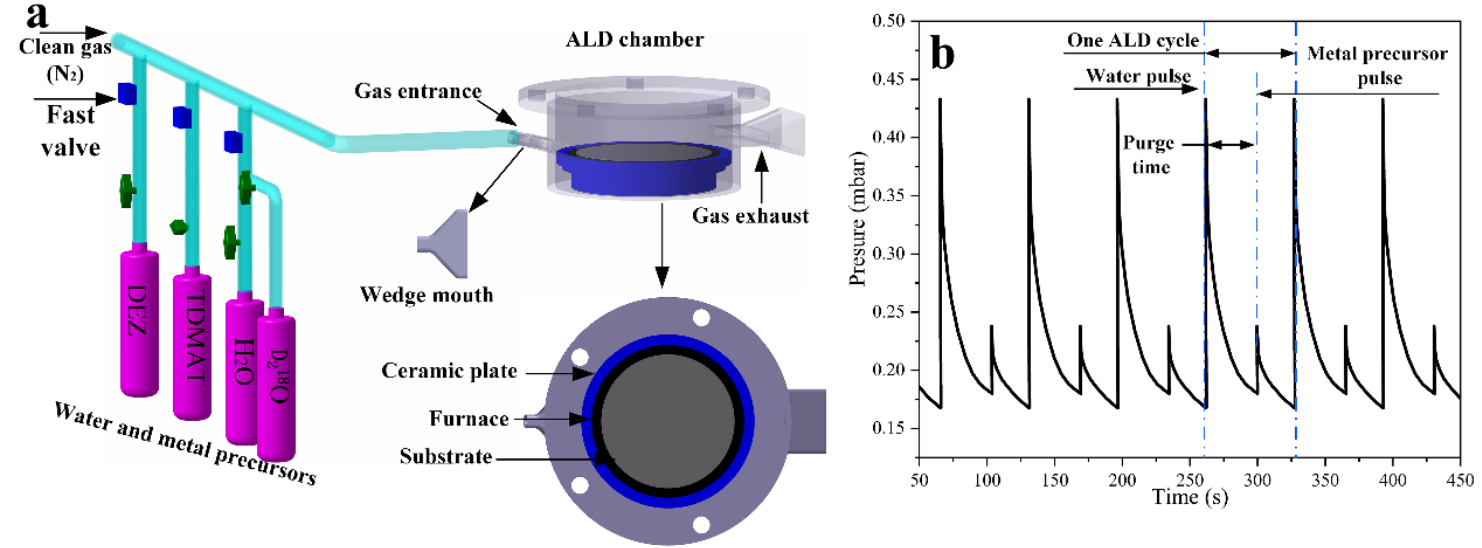

Fig. 1. a: Home-made ALD system included deposition chamber; b: the signal of pulse time of water and metal precursors 


\subsection{Experiment description}

Si (100) wafers cleaned with acetone followed by absolute ethanol were used as the substrate. Diethlyzinc (DEZ), Tetrakis (dimethylamino)titanium (TDMAT) and water were used as precursors. The pulse time of DEZ and TDMAT was fixed at $15 \mathrm{~ms}$ and $200 \mathrm{~ms}$ respectively, and the injection time of water was varied from $15 \mathrm{~ms}$ to $100 \mathrm{~ms}$. A long $\mathrm{N}_{2}$ purge time (30s) was applied in order to prevent precursors mixing during deposition. The sample surface temperature was varied from $100^{\circ} \mathrm{C}$ to $300^{\circ} \mathrm{C}$ and the number of ALD cycles was varied from 5 to 40 for growth of $\mathrm{ZnO}$ films and from 5 to150 for growth of $\mathrm{TiO}_{2}$ films. The detailed parameters for deposition $\mathrm{ZnO}$ and $\mathrm{TiO}_{2}$ films are summarized in table 1. In this paper, we will present films grown using water of natural isotopic composition, and water highly enriched in deuterium and in ${ }^{18} \mathrm{O}$.

Table 1. Typical ALD deposition parameters for $\mathrm{ZnO}$ and $\mathrm{TiO}_{2}$

\begin{tabular}{|l|l|}
\hline Process parameters & Conditions \\
\hline DEZ & Pulse $15 \mathrm{~ms}+$ purge $30 \mathrm{~s}$ \\
\hline TDMAT & Pulse $200 \mathrm{~ms}+$ purge $30 \mathrm{~s}$ \\
\hline $\mathrm{H} 2 \mathrm{O} / \mathrm{D}_{2}{ }^{18} \mathrm{O}$ & Pulse $15-100 \mathrm{~ms}+$ purge $30 \mathrm{~s}$ \\
\hline ALD cycles & DEZ: $5-40$ cycles; TDMAT:50-150 cycles \\
\hline Temperature $\left({ }^{\circ} \mathrm{C}\right)$ & $100-300^{\circ} \mathrm{C}$ \\
\hline Pressure $(\mathrm{pa})$ & $50-70 \mathrm{pa}$ \\
\hline
\end{tabular}

\subsection{The characterization techniques}

RBS and NRA were performed on the SAFIR platform of Sorbonne University, Paris. Backscattering Spectrometry (RBS) was used to determine the $\mathrm{Zn}$ and Ti area density, employed $20-100 \mathrm{nA}^{4} \mathrm{He}^{+}$beams of $1.8-2.1 \mathrm{MeV}$, in a $1 \mathrm{~mm}$ diameter beamspot, with particle detection at $165^{\circ}$ scattering angle. The detector solid angle was calibrated with 3\% uncertainty using a Bi-implanted reference sample $[17,18]$. Nuclear Reaction Analysis (NRA) was used to measure the ${ }^{16} \mathrm{O}$ areal densities via the ${ }^{16} \mathrm{O}\left(\mathrm{d}, \mathrm{p}_{1}\right){ }^{17} \mathrm{O}$ nuclear reactions, with respect to a thermal $\mathrm{SiO}_{2}$ film, with $\left[{ }^{16} \mathrm{O}\right]=624.8 \times 10^{15}$ atoms $/ \mathrm{cm}^{2}$ as deduced from the film thickness and density determined by ellipsometry[19]. An $860 \mathrm{keV}$ deuteron beam of $85 \mathrm{nA}$ in a $2 \mathrm{~mm}$ beamspot was used, and the protons produced by the nuclear reactions were detected at $150^{\circ}$ in a $300 \mathrm{~mm}^{2}$ detector behind a 13 mylar foil which stopped the high flux of elastically scattered deuterons from saturating the detector. ${ }^{18} \mathrm{O}$ was determined by the ${ }^{18} \mathrm{O}(\mathrm{p}, \alpha){ }^{15} \mathrm{~N}$ nuclear reaction with $85 \mathrm{nA}$ of $750 \mathrm{keV}$ protons in a $2 \mathrm{~mm}$ beamspot, and the alpha particles detected at $150^{\circ}$ in a $300 \mathrm{~mm}^{2}$ detector behind a $13 \mu$ m mylar film. The physical film thickness obtained from spectroscopic ellipsometry (SE) with a FS-1 Multi- 
Wavelength Ellipsometer system in the wavelength range of 465-635 nm at an angle of incidence of $65^{\circ}$.

\section{Results and discussion}

\subsection{The growth of $\mathrm{ZnO}$}

Fig.2 shows the growth per ALD cycle measured by ellipsometry as a function of the substrate surface temperature with a DEZ precursor pulse time of $15 \mathrm{~ms}$ and $\mathrm{H}_{2} \mathrm{O}$ pulse time of $100 \mathrm{~ms}$ for each cycle. The resulting film thickness ranged from 16 to $60 \mathrm{~nm}$. The highest growth rate, of about $14 \AA$ /cycle, occurs in a temperature window between $140{ }^{\circ} \mathrm{C}$ and $175^{\circ} \mathrm{C}$. At substrate temperatures outside this range the growth rate falls. At lower substrate surface temperatures the DEZ precursors might not have sufficient energy to react with the - $\mathrm{OH}$ groups on the surface [15]. At temperatures above $175^{\circ} \mathrm{C}$ M. Rueter [20] has proposed that the lowered growth rate is due to surface thermal decomposition of the DEZ. In our system, although the chamber is not deliberately heated thermal radiation from the substrate still increases the temperature of the elements surrounding the substrate plate, including the chamber walls, where the DEZ may be decomposed into $\mathrm{Zn}$ and ethyl fragments, inhibiting growth on the substrate. The stable growth rate in the temperature window between 140 and $175^{\circ} \mathrm{C}$ suggests that self-limiting ALD growth of $\mathrm{ZnO}$ films has been obtained, as has been observed for very similar ALD windows in previous works [21-23].

The number of water molecules adsorbed on the surface is related to the pulse time, whilst substrate temperature has a strong influence on the formation of $-\mathrm{OH}$ groups formed from the adsorbed water molecules. We therefore investigated the influence of water pulse time on ALD growth within the ALD window. In Fig 3a, we show the number of $\mathrm{Zn}$ atoms (determined by RBS) as a function of number of cycles for water pulse times of 15,50 and $100 \mathrm{~ms}$. In all cases film growth is achieved, and after about 10 cycles the growth rate increases as the water pulse time is increased. Clearly, for the shorter water pulse times full coverage of the surface by -OH groups is not achieved. During the first 10 or so cycles, the growth rate is limited by the surface group preparation, as is commonly observed $[24,25]$. Here, the substrate surface is still very smooth as measured by AFM with value about $\mathrm{Rq}=0.38 \mathrm{~nm}$, whereas after the initial cycles the substrate surface can become rougher and facilitate adsorption of water molecules. In Fig $3 \mathrm{~b}$, the ratio of $\mathrm{Zn}$ to $\mathrm{O}$ atoms is plotted as a function of the number of ALD cycles for the 3 water pulse times. The films are all initially deficient in $\mathrm{Zn}$ for the first growth cycles, however the ratio of $\mathrm{Zn}$ to oxygen increases as water pulse time increases.

This indicates that when the surface is inadequately covered with -OH groups, the reaction of DEZ with the -OH groups is hindered, and it is possible that some of DEZ desorbs from the surface in regions where the $-\mathrm{OH}$ coverage is low. Previous study also illustrated that substrate-inhibited growth is caused by a lower number of reactive sites on the substrate than on the ALD-grown material $[26,27]$. Since the depth resolution of NRA is unable to distinguish between ${ }^{16} \mathrm{O}$ in the native oxide of the silicon substrate and that in the overlying $\mathrm{ZnO}$ films, we have systematically subtracted the amount of oxygen in the substrate, as measured on an untreated virgin substrate from the same silicon wafer, from the oxygen contents measured for the "substrate plus film" samples. 
There remains, however, some uncertainty about the actual number of oxygen atoms in the substrate oxide layer after the first ALD cycles and it is not yet clear to what extent possible underestimation of the substrate oxide film thickness (after the initial ALD cycles) could be responsible for the observed low $\mathrm{ZnO}$ ratios for very thin $\mathrm{ZnO}$ layers obtained after the first 5 to 15 cycles.

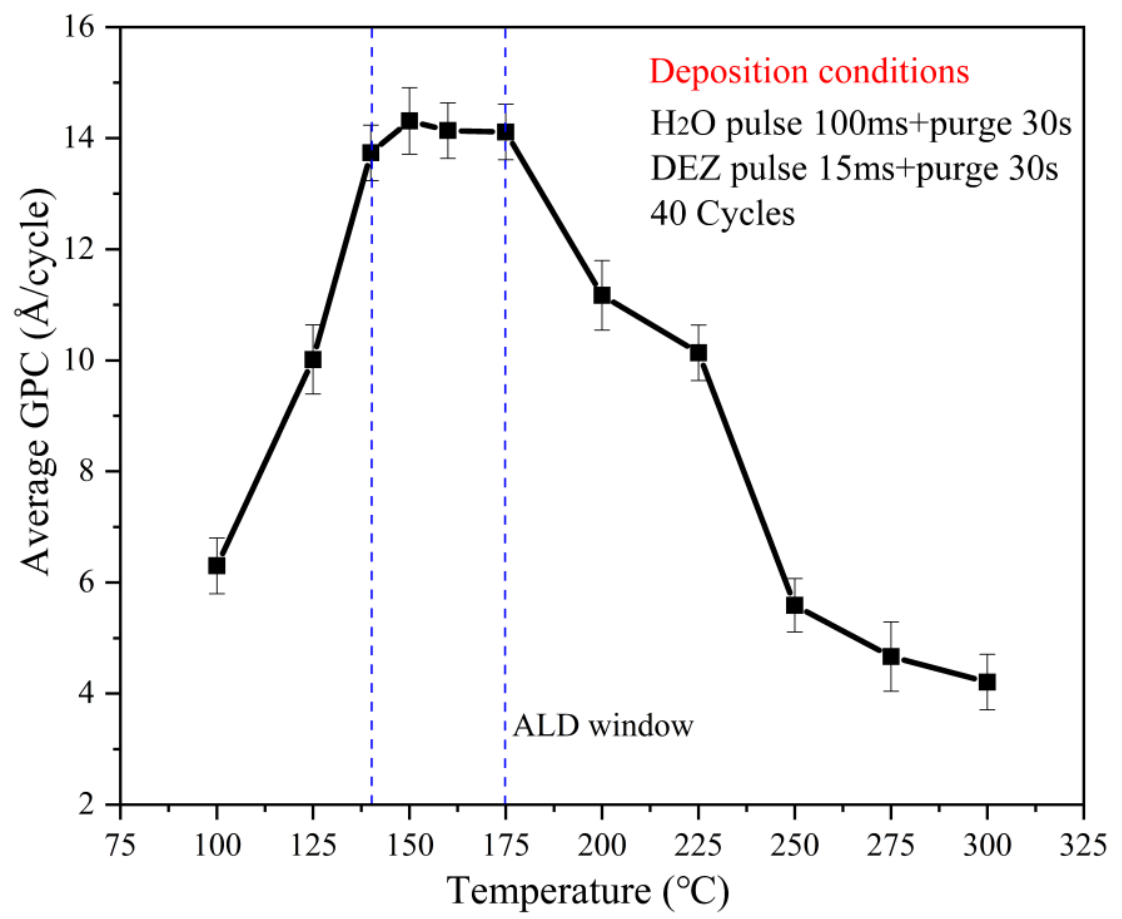

Fig.2. The variation in growth rate of $\mathrm{ZnO}$ films as a function of the substrate surface temperature.

The number of ALD cycle was kept at 40 cycles.
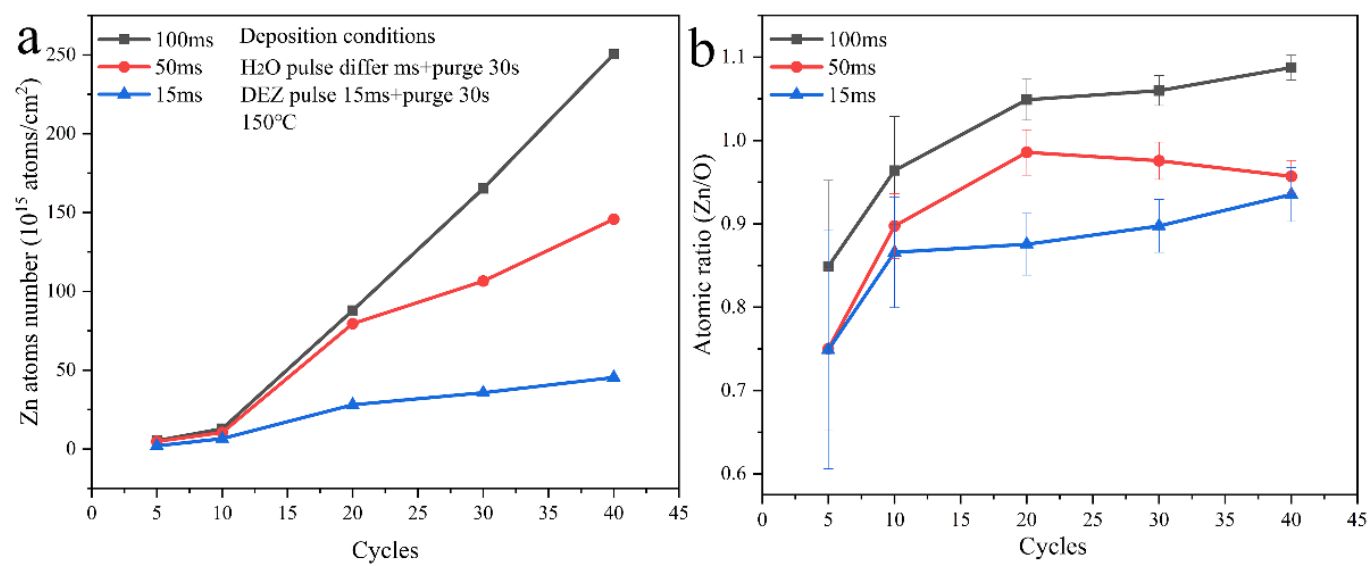

Fig.3. a: The variation in growth rate of $\mathrm{ZnO}$ films as a function of the $\mathrm{ALD}$ cycles at $150^{\circ} \mathrm{C}$; $\mathrm{b}$ the variation in atomic ratio of $\mathrm{Zn} / \mathrm{O}$ as a function of the $\mathrm{ALD}$ cycles at $150^{\circ} \mathrm{C}$

\subsection{The growth of $\mathrm{TiO}_{2}$}

Fig. 4 shows the growth rate of $\mathrm{TiO}_{2}$ as a function of the substrate surface temperature with a given TDMAT precursor time of $200 \mathrm{~ms}$ and $\mathrm{H}_{2} \mathrm{O}$ precursor time of $100 \mathrm{~ms}$. At low temperature, the film growth rate is much higher than at high temperature. It has been shown $[28,29]$ that TDMAT has an activation energy of just $16 \mathrm{~kJ} / \mathrm{mol}(0.17 \mathrm{eV})$ for adsorption in the low-temperature regime, 
indicating a thermally activated adsorption surface process. In other words, numerous TDMAT molecules have an energy sufficient for adsorption to the low temperature surface which causes a high growth rate at the low temperature. The growth rate will decrease as the sample surface temperature is increased from $100^{\circ} \mathrm{C}$ to $250^{\circ} \mathrm{C}$. This behavior is different from many models of ALD processes in the low temperature region. For this case, temperature programmed desorption (TPD) showed that the most of the TDMAT desorbed from the surface as the temperature was increased [30]. Hence, the growth rate of $\mathrm{TiO}_{2}$ films will initially reduce with increasing surface temperature. We note that as the temperature is further increased, the growth rate of $\mathrm{TiO}_{2}$ films increases. The increase in growth rate above $250^{\circ} \mathrm{C}$ is probably due to chemical vapor deposition (CVD) attributed to the gas phase decomposition of TDMAT. The team of Elam et al. also reported that the decomposition of TDMAT become more important for ALD deposition of $\mathrm{TiO}_{2}$ at high temperature [31].

Based on the study of influence of substrate temperature on deposition, it was chosen to study the process at low temperature because the growth rate is very high - a clear advantage for commercial application. Hence, the temperature of $100^{\circ} \mathrm{C}$ was selected to study the effect of the water pulse duration, which was varied from $15 \mathrm{~ms}$ to $100 \mathrm{~ms}$. In Fig. $5 \mathrm{a}$ we observe that for $15 \mathrm{~ms}$ pulse time, the growth rate of $\mathrm{TiO}_{2}$ films is clearly lower than that for $50 \mathrm{~ms}$ and $100 \mathrm{~ms}$ water pulses. The increase of film growth rate with water pulse duration strongly demonstrates that an adequate amount of water needs to be supplied during the ALD process. For the explanation of the increase of growth rate, although deposition of the water and $-\mathrm{OH}$ on rutile $\mathrm{TiO}_{2}$ surface is temperatureindependent [32], higher water exposure will likely lead to higher water and -OH coverage, providing more active sites for TDMAT reaction. We also observe, in Fig. 5b, that the Ti/O atomic ratio is highest for the samples grown with $100 \mathrm{~ms}$ water pulses, further supporting that view that the shorter water pulse times didn't provide enough active sites for TDMAT reaction.

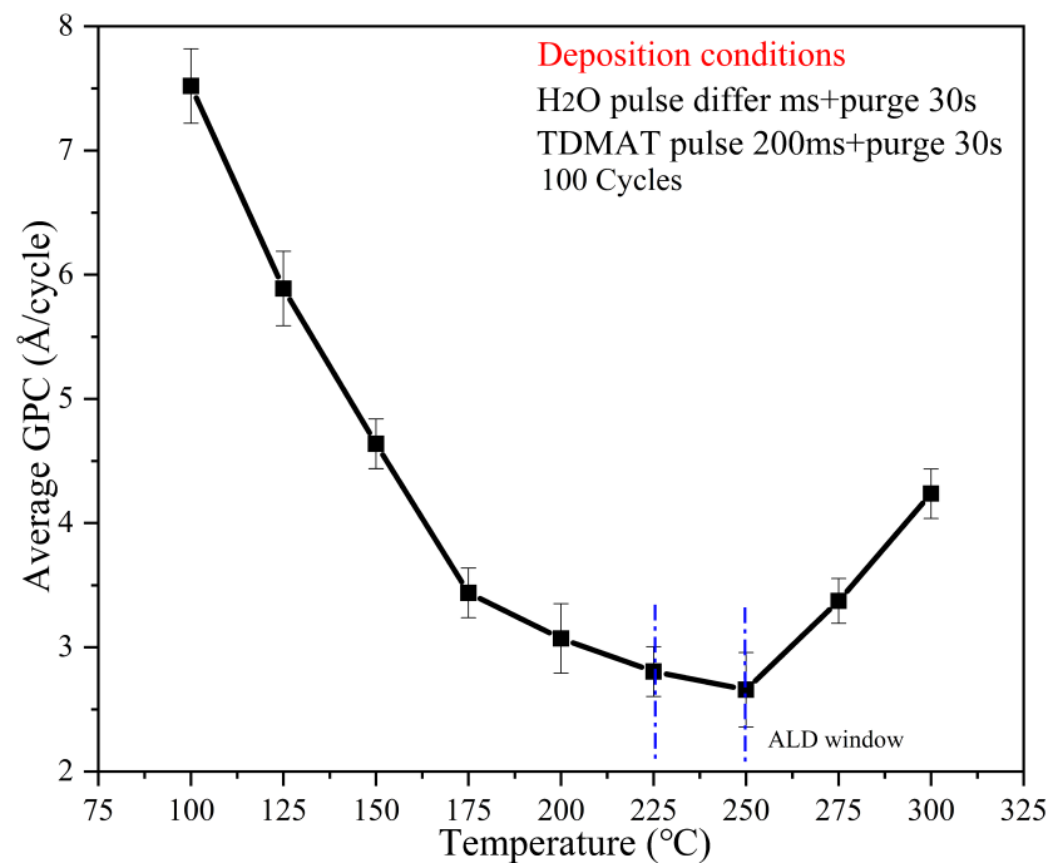

Fig.4. The variation in growth rate of $\mathrm{TiO}_{2}$ films as a function of the substrate surface temperature.

The number of ALD cycle was kept at 100 cycles. 

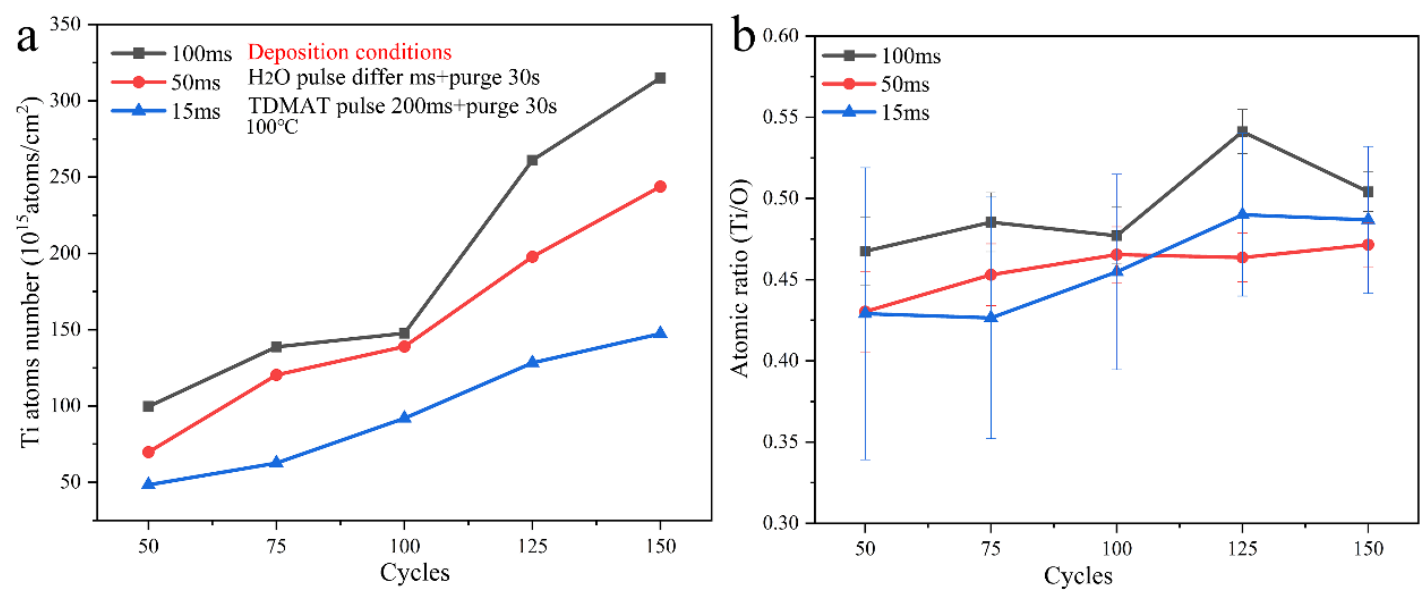

Fig.5. a: The variation in growth rate of $\mathrm{TiO}_{2}$ films as a function of the $\mathrm{ALD}$ cycles at $100^{\circ} \mathrm{C} ; \mathrm{b}$ the variation in atomic ratio of Ti/O as a function of the $\mathrm{ALD}$ cycles at $100^{\circ} \mathrm{C}$

\subsection{Double layer and multilayer films}

Based on the previous experiments, double layer films with 50 ALD cycles for $\mathrm{ZnO}$ and $100 \mathrm{ALD}$ cycles for $\mathrm{TiO}_{2}$ were prepared at the single temperature of $225^{\circ} \mathrm{C}$, which is within the ALD window for $\mathrm{TiO}_{2}$ and slightly above it for $\mathrm{ZnO}$, in view of preparing multilayer films, for which using separate temperatures for each layer would require substantial deadtime for temperature equilibration between the growth of each layer. Films were prepared for $\mathrm{ZnO}$-first and for $\mathrm{TiO}_{2}$-first growth. Fig 6 shows the RBS spectra measured with $1.5 \mathrm{MeV}^{4} \mathrm{He}$ incident ions, and the respective best SimNRA [33] fits, for the $\mathrm{TiO}_{2}$-first (Fig 6a) and ZnO-first (Fig 6b) systems. We may note that the film thicknesses are not the same under the two different growth orders: the growth of $\mathrm{ZnO}$ on $\mathrm{TiO}_{2}$ is accelerated compared with that of $\mathrm{ZnO}$ on the Si substrate, whilst the growth of $\mathrm{TiO}_{2}$ on $\mathrm{ZnO}$ is retarded with respect to that of $\mathrm{TiO}_{2}$ on the silicon substrate. To our knowledge this has not been reported previously, and we do not have an explanation for this observation, however further work studying the effect of the thickness of the $\mathrm{TiO}_{2}$ layer on the acceleration of the $\mathrm{ZnO}$ growth, and the detailed growth kinetics (does the growth rate enhancement reduces as the $\mathrm{ZnO}$ film thickness increases?) should throw significant light on the underlying processes.

a
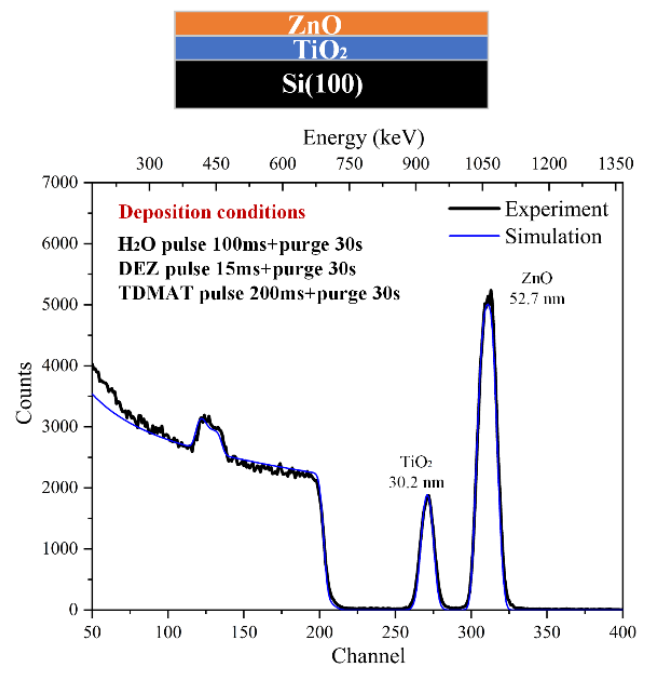

b
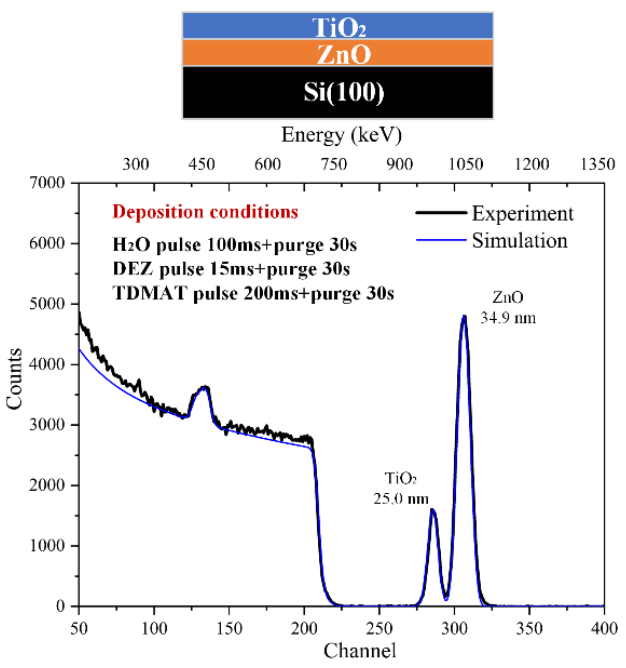


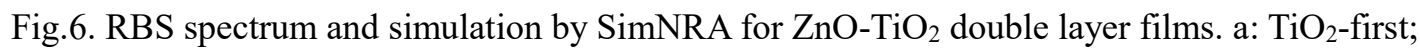

b: ZnO-first.

$\mathrm{ZnO} / \mathrm{TiO}_{2}$ multilayer films were deposited onto $\mathrm{Si}(100)$ substrates by repeating $80 \mathrm{TiO}_{2} \mathrm{ALD}$ cycles and $30 \mathrm{ZnO}$ ALD cycles at $225^{\circ} \mathrm{C}$ with the same precursor, water and purge times as for the bilayers described above. The RBS spectrum measured with $2.05 \mathrm{MeV}^{4} \mathrm{He}$ incident ions is shown in Fig. 7a. The Ti and $\mathrm{Zn}$ peaks from the 6 layers are well separated, indicating well-defined $\mathrm{TiO}_{2}$ and $\mathrm{ZnO}$ layers, and the spectrum can be fitted well by SimNRA. The layer thicknesses are given in table 2 from top to bottom. The $\mathrm{TiO}_{2}$ film thicknesses are quite uniform and in this case we do not observe the retarding of the $\mathrm{TiO}_{2}$ growth rate on $\mathrm{ZnO}$ compared to that of $\mathrm{TiO}_{2}$ on the substrate. We do note, though, that the growth rate of layer 5 (the first $\mathrm{ZnO}$ layer, on $\mathrm{TiO}_{2}$ ) has been accelerated as was observed in the bilayer system. These observations indicate that there may remain some uncontrolled parameters, such as thermal inertia in the substrate holder or surrounding elements, or chemical memory effects in our growth system. Table 2 also presents the density of each layer, for the $\mathrm{ZnO}$ layer, the density is little lower than the $\mathrm{ZnO}$ bulk density with value $5.61 \mathrm{~g} / \mathrm{cm}^{3}$, the density of $\mathrm{TiO}_{2}$ is closed to the rutile density of $\mathrm{TiO}_{2}\left(4.23 \mathrm{~g} / \mathrm{cm}^{3}\right)$.

Table 2. The thickness of each layer for multilayer film

\begin{tabular}{|c|c|c|c|c|}
\hline \multicolumn{2}{|c|}{ Layer } & $10^{15}$ Atoms $/ \mathrm{cm}^{2}$ & Thickness(nm) & Density $\left(\mathrm{g} / \mathrm{cm}^{3}\right)$ \\
\hline 1 & $\mathrm{ZnO}$ & 252.0 & 30.7 & 5.5 \\
\hline 2 & $\mathrm{TiO}_{2}$ & 150.0 & 15.6 & 4.1 \\
\hline 3 & $\mathrm{ZnO}$ & 245.0 & 30.4 & 5.4 \\
\hline 4 & $\mathrm{TiO}_{2}$ & 150.0 & 15.6 & 4.1 \\
\hline 5 & $\mathrm{ZnO}$ & 312.0 & 37.7 & 5.5 \\
\hline 6 & $\mathrm{TiO}_{2}$ & 145.0 & 15.1 & 4.0 \\
\hline \multicolumn{5}{|c|}{$\mathrm{Si}(100)$} \\
\hline
\end{tabular}

Fig. $7 \mathrm{~b}$ shows the RBS spectrum of a $\mathrm{ZnO}$ film grown using water highly enriched in $\mathrm{D}^{218} \mathrm{O}$. We note here that the actual amount of water consumed for the growth of the film was too small to be observed, and we estimate that a few $\mathrm{cm}^{3}$ of enriched water will be sufficient for many hundreds of hours of operation.

The presence of both isotopes $-{ }^{18} \mathrm{O}$ and ${ }^{16} \mathrm{O}$ - is clear from the RBS spectrum but due to high background from the Si substrate and the resulting high uncertainties in estimating the areas under the oxygen signals, areal densities of ${ }^{16} \mathrm{O}$ and ${ }^{18} \mathrm{O}$ were measured precisely by NRA under conditions previously described [34]. Nevertheless, the RBS spectra do show that the two isotopes are present throughout the thickness of the films, and the simulated RBS spectrum using the quantities of ${ }^{18} \mathrm{O}$ and ${ }^{16} \mathrm{O}$ derived from NRA (given in the inset) are fully compatible with the measured RBS spectrum.

Although the water used was almost fully enriched in ${ }^{18} \mathrm{O}$, the film contains about $30 \%{ }^{16} \mathrm{O}$. The total amount of ${ }^{16} \mathrm{O}$, of $100 \times 10^{15} \mathrm{atoms} / \mathrm{cm}^{2}$, is far greater than that of the substrate native oxide and so must come almost entirely from the growth process, and probably from water adsorbed on the manifold, piping and chamber walls. This indicates that for future isotopic tracing studies of 
growth mechanisms, special attention will need to be paid to outgassing the entire ALD system between growth sequences using different isotopically distinct water sources. We do note, that ALD films enriched even only to $70 \%$ in ${ }^{18} \mathrm{O}$ will be very useful for the study of annealing processes under standard conditions such as flowing air.
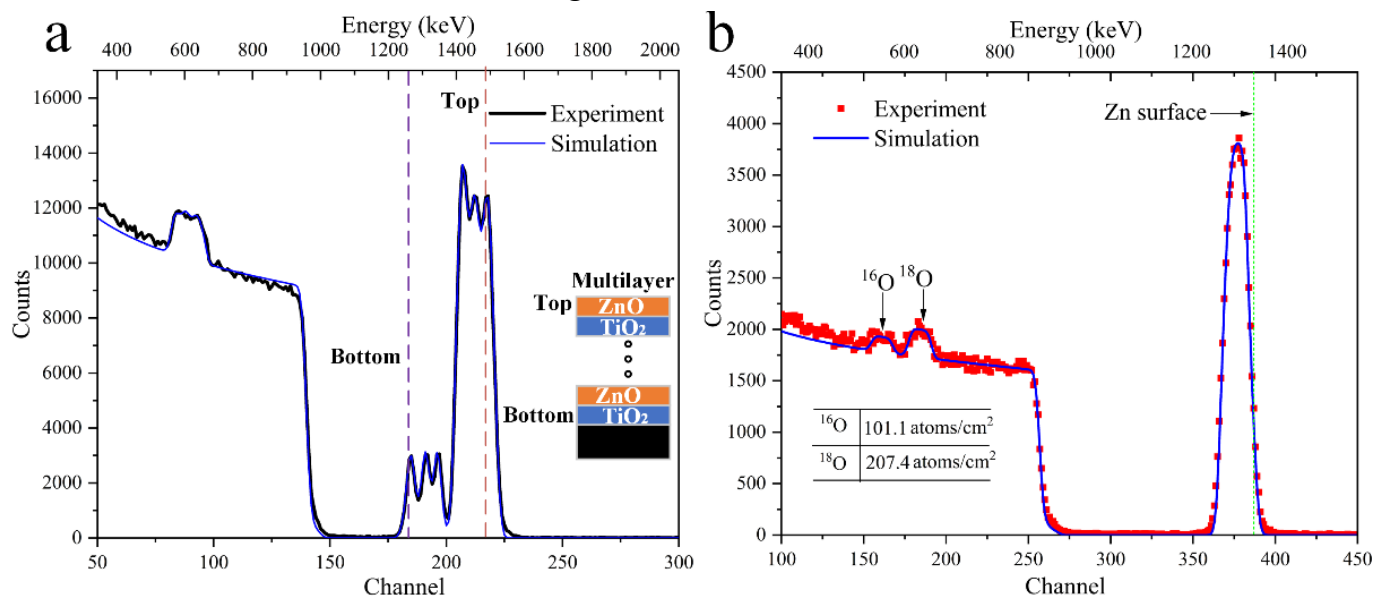

Fig.7. a: The RBS spectrum at $2.05 \mathrm{MeV}$ simulated by SimNRA. b: RBS spectrum and SimNRA simulation for ${ }^{18} \mathrm{O}$ enriched $\mathrm{ZnO}$ films.

\section{Conclusions}

We have successfully developed a home-made ALD system with high growth rates compared with established commercial systems. The system has been successfully demonstrated to grow stoichiometric $\mathrm{ZnO}$ and $\mathrm{TiO}_{2}$ films, bilayers and multilayers. The small volume has enabled production of films highly enriched in ${ }^{18} \mathrm{O}$, using only very small quantities of the expensive isotopically enriched water source.

\section{Acknowledgement}

The ALD system is funded in part by the CEMIP (Centre de Microélectronique de Paris Ile-de-France). The work has also benefitted from the support of the SAFIR platform of Sorbonne Université, and dedicated internal funding from the Institut des NanoSciences de Paris. We also acknowledge useful discussions with members of the French ALD network RAFALD. B. Xia is funded by the China Scholarship Council for his $\mathrm{PhD}$ studies. 


\section{Reference}

[1] T. Suntola, И Materials Sci, Reports. 4(7) (1989) 261.

[2] M. Ritala, M. Leskelä, J.P. Dekker, C. Mutsaers, P.J. Soininen, J. Skarp, Perfectly conformal TiN and Al2O3 films deposited by atomic layer deposition, Chemical Vapor Deposition 5(1) (1999) 7 9.

[3] T. Hirvikorpi, M. Vähä-Nissi, J. Nikkola, A. Harlin, M. Karppinen, Thin Al2O3 barrier coatings onto temperature-sensitive packaging materials by atomic layer deposition, Surface and Coatings Technology 205(21-22) (2011) 5088-5092.

[4] F. Zaera, The surface chemistry of thin film atomic layer deposition (ALD) processes for electronic device manufacturing, Journal of Materials Chemistry 18(30) (2008) 3521-3526.

[5] P. Carcia, R. McLean, M. Reilly, High-performance $\mathrm{ZnO}$ thin-film transistors on gate dielectrics grown by atomic layer deposition, Applied physics letters 88(12) (2006) 123509.

[6] A. Richter, J. Benick, M. Hermle, S.W. Glunz, Excellent silicon surface passivation with $5 \AA$ thin ALD Al2O3 layers: Influence of different thermal post-deposition treatments, physica status solidi (RRL)-Rapid Research Letters 5(5-6) (2011) 202-204.

[7] I.J. Raaijmakers, Current and future applications of ALD in micro-electronics, ECS Transactions 41(2) (2011) 3-17.

[8] Y. Ye, C. Jo, I. Jeong, J. Lee, Functional mesoporous materials for energy applications: solar cells, fuel cells, and batteries, Nanoscale 5(11) (2013) 4584-4605.

[9] P. Poodt, R. Knaapen, A. Illiberi, F. Roozeboom, A. van Asten, Low temperature and roll -toroll spatial atomic layer deposition for flexible electronics, Journal of Vacuum Science \& Technology A: Vacuum, Surfaces, and Films 30(1) (2012) 01A142.

[10] A.P. Peter, K. Martens, G. Rampelberg, M. Toeller, J.M. Ablett, J. Meersschaut, D. Cuypers, A. Franquet, C. Detavernier, J.P. Rueff, Metal-Insulator Transition in ALD VO2 Ultrathin Films and Nanoparticles: Morphological Control, Advanced Functional Materials 25(5) (2015) 679-686.

[11] P. Verdonck, A. Delabie, J. Swerts, L. Farrell, M. Baklanov, H. Tielens, E. Van Besien, T. Witters, L. Nyns, S. Van Elshocht, Chemisorption of ALD precursors in and on porous low-k films, Microelectronic engineering 106 (2013) 81-84.

[12] V. Drozd, I. Nikiforova, V. Bogevolnov, A. Yafyasov, E. Filatova, D. Papazoglou, ALD synthesis of SnSe layers and nanostructures, Journal of Physics D: Applied Physics 42(12) (2009) 125306.

[13] Y.-J. Choi, S.C. Gong, D.C. Johnson, S. Golledge, G.Y. Yeom, H.-H. Park, Characteristics of the electromagnetic interference shielding effectiveness of Al-doped $\mathrm{ZnO}$ thin films deposited by atomic layer deposition, Applied Surface Science 269 (2013) 92-97.

[14] D.H. Levy, D. Freeman, S.F. Nelson, P.J. Cowdery-Corvan, L.M. Irving, Stable ZnO thin film transistors by fast open air atomic layer deposition, Applied Physics Letters 92(19) (2008) 192101.

[15] S.K. Kim, S. Hoffmann-Eifert, M. Reiners, R. Waser, Relation between enhancement in growth and thickness-dependent crystallization in ALD TiO2 thin films, Journal of The Electrochemical Society 158(1) (2011) D6-D9.

[16] M. Ritala, M. Leskelä, Atomic layer deposition, Handbook of Thin Films, Elsevier2002, pp. 103-159.

[17] J. Davies, T. Jackman, H. Eschbach, W. Dobma, U. Wätjen, D. Chivers, Calibration of the Harwell series II Bi-implanted RBS standards, Nuclear Instruments and Methods in Physics Research Section B: Beam Interactions with Materials and Atoms $15(1-6)$ (1986) 238-240. 
[18] L. Lemelle, F. Abel, C. Cohen, F. Guyot, Study of the (010) olivine surface by Rutherford backscattering spectrometry in channeling geometry, American Mineralogist 87(2-3) (2002) 327 332.

[19] I. Volintiru, M. Creatore, M. Van De Sanden, In situ spectroscopic ellipsometry growth studies on the Al-doped $\mathrm{ZnO}$ films deposited by remote plasma-enhanced metalorganic chemical vapor deposition, Journal of applied physics 103(3) (2008) 033704.

[20] M. Rueter, J. Vohs, The surface reactions of ethyl groups on Si (100) formed via dissociation of adsorbed diethylzinc, Surface science 262(1-2) (1992) 42-50.

[21] E. Guziewicz, M. Godlewski, L. Wachnicki, T.A. Krajewski, G. Luka, S. Gieraltowska, R. Jakiela, A. Stonert, W. Lisowski, M. Krawczyk, ALD grown zinc oxide with controllable electrical properties, Semiconductor Science and Technology 27(7) (2012) 074011.

[22] D. Kim, H. Kang, J.-M. Kim, H. Kim, The properties of plasma-enhanced atomic layer deposition (ALD) ZnO thin films and comparison with thermal ALD, Applied Surface Science 257(8) (2011) 3776-3779.

[23] E. Janocha, C. Pettenkofer, ALD of ZnO using diethylzinc as metal-precursor and oxygen as oxidizing agent, Applied Surface Science 257(23) (2011) 10031-10035.

[24] R.L. Puurunen, W. Vandervorst, Island growth as a growth mode in atomic layer deposition: A phenomenological model, Journal of Applied Physics 96(12) (2004) 7686-7695.

[25] S. Lee, Y.H. Im, Y.-B. Hahn, Two-step growth of ZnO films on silicon by atomic layer deposition, Korean Journal of Chemical Engineering 22(2) (2005) 334-338.

[26] M. Green, M.-Y. Ho, B. Busch, G. Wilk, T. Sorsch, T. Conard, B. Brijs, W. Vandervorst, P. Räisänen, D. Muller, Nucleation and growth of atomic layer deposited HfO 2 gate dielectric layers on chemical oxide ( $\mathrm{Si}-\mathrm{O}-\mathrm{H}$ ) and thermal oxide ( $\mathrm{SiO} 2$ or $\mathrm{Si-O}-\mathrm{N}$ ) underlayers, Journal of Applied Physics 92(12) (2002) 7168-7174.

[27] A.M. Hoyas, J. Schuhmacher, D. Shamiryan, J. Waeterloos, W. Besling, J.-P. Celis, K. Maex, Growth and characterization of atomic layer deposited WC 0.7 N 0.3 on polymer films, Journal of applied physics 95(1) (2004) 381-388.

[28] J.B. Hudson, T.L. Einstein, <i>Surface Science: An Introduction</i>, Materials Today 45(12) 85-86.

[29] E.T. Norton, C. Amato-Wierda, Kinetic and mechanistic studies of the thermal decomposition of $\mathrm{Ti}(\mathrm{N}(\mathrm{CH} 3)$ 2) 4 during chemical vapor deposition by in situ molecular beam mass spectrometry, Chemistry of materials 13(12) (2001) 4655-4660.

[30] J. Corneille, P. Chen, C. Truong, W. Oh, D. Goodman, Surface spectroscopic studies of the deposition of TiN thin films from tetrakis-(dimethylamido)-titanium and ammonia, Journal of Vacuum Science \& Technology A: Vacuum, Surfaces, and Films 13(3) (1995) 1116-1120.

[31] J. Elam, M. Schuisky, J.D. Ferguson, S. George, Surface chemistry and film growth during TiN atomic layer deposition using TDMAT and NH3, Thin Solid Films 436(2) (2003) 145-156.

[32] B. Abendroth, T. Moebus, S. Rentrop, R. Strohmeyer, M. Vinnichenko, T. Weling, H. St?cker, D.C. Meyer, Atomic layer deposition of $\mathrm{TiO} 2$ from tetrakis(dimethylamino)titanium and $\mathrm{H} 2 \mathrm{O}$, Thin Solid Films 545 176-182.

[33] M. Mayer, SIMNRA User's Guide, Report IPP 9/113, Max-Planck-Institut fur Plasmaphysik, Garching, Germany (1997), There is no corresponding record for this reference.[Google Scholar]. [34] G. Amsel, J. Nadai, E. d'Artemare, D. David, E. Girard, J. Moulin, Microanalysis by the direct observation of nuclear reactions using a $2 \mathrm{MeV}$ Van de Graaff, Nuclear instruments and methods 
92(4) (1971) 481-498. 